\title{
Intercellular adhesive molecule-1 (ICAM-1) in proliferative diabetic retinopathy
}

\author{
Andi A. Victor ${ }^{1}$, Tjahjono D. Gondhowiardjo', Rahayuningsih \\ Dharma ${ }^{2}$, Sri W. A. Jusman ${ }^{3}$, Vivi R. Yandrii ${ }^{4}$ Ressa Yuneta ${ }^{4}$, \\ Rizky E. P. Yuriza ${ }^{4}$ \\ ${ }^{1}$ Department of Ophthalmology, Faculty of Medicine, Universitas Indonesia, \\ Jakarta, Indonesia; ${ }^{2}$ Department of Clinical Pathology, Faculty of Medicine, \\ Universitas Indonesia, Jakarta, Indonesia; ${ }^{3}$ Department of Biochemistry and \\ Molecular Biology, Faculty of Medicine, Universitas Indonesia, Jakarta, Indonesia; \\ ${ }^{4}$ Faculty of Medicine, Universitas Indonesia, Jakarta, Indonesia
}

\begin{abstract}
Purpose: To determine the level of intercellular adhesion molecule-1 (ICAM-1) in vitreous fluid of patients with proliferative diabetic retinopathy (PDR) and its affecting factors including HbA1c level, duration of diabetes mellitus (DM) and insulin usage.

Methods: A cross-sectional study was conducted in Cipto Mangunkusumo National General Central Hospital, Jakarta, Indonesia from June 2015 to August 2016. Thirty-three consecutive vitreous samples harvested from PDR patients underwent vitrectomy. The level of vitreous ICAM-1 was determined by enzyme-linked immunosorbent assay.

Results: Based on the glycemic status, vitreous ICAM-1 level in the uncontrolled glycemic group $(21.61 \mathrm{ng} / \mathrm{ml})$ was lower than controlled glycemic group $(24.20 \mathrm{ng} / \mathrm{ml})$. Patients with DM for more than 10 years had higher level of vitreous ICAM-1 $(26.30 \mathrm{ng} / \mathrm{ml})$. Vitreous ICAM-1 level in DM patients with insulin was higher than those without insulin (27.07 ng/m/ vs. $24.17 \mathrm{ng} / \mathrm{ml})$. There was no statistically significant difference between vitreous ICAM-1 levels among all groups ( $p>0.05)$.

Conclusion: The concentration of vitreous ICAM-1 may not be influenced by glucose control and conventional insulin therapy.
\end{abstract}

Keywords: diabetic retinopathy, insulin, intercellular adhesion molecule-1, type 2 diabetes mellitus

\section{Introduction}

Diabetic retinopathy (DR) is a serious micro-vascular complication of type 2 diabetes mellitus (T2DM) resulting in visual impairment and blindness, affecting those in productive age. ${ }^{1,2}$ The advanced stage of $D R$, proliferative diabetic retinopathy (PDR), is characterized by neovascularization and epiretinal outgrowth of

Correspondence: Andi A. Victor, MD, PhD, Vitreoretinal Division, Department of Ophthalmology, Faculty of Medicine, University of Indonesia, Cipto Mangunkusumo Hospital-Kirana, Jl. Kimia no. 8, Menteng, Central Jakarta, DKI Jakarta, Indonesia 10320 E-mail:arvimadao@yahoo.com 
fibrovascular membranes (FVMs) in the retina. This fibrovascular tissue could progress into tractional retinal detachment and vitreous haemorrhage leading to visual loss. ${ }^{3,4}$

DR is the most common retinal vascular disorder found in Cipto Mangunkusumo General Hospital (CMGH), Indonesia. Based on preliminary study of 3,988 medical records, $60 \%$ of DR patients who were hospitalized from 2004 to 2009 suffered from non-PDR, while the remaining suffered from PDR. In 2010 to 2012, the percentage of PDR patients increased to $47.9 \%$, suggesting increased number of PDR patients over the years.

Despite the effort of early detection and tight glucose control in T2DM patients, the number of PDR cases is still rising. In addition, advances in treatment of PDR remains constant, adding more burdens to the problem.

Recent studies have found novel factors involved in the progression of PDR, one of which is intercelullar adhesion molecule-1 (ICAM-1). ${ }^{5}$ ICAM-1 is an intercellular adhesion molecular whose production is triggered by vascular endothelial growth factor (VEGF) and plays vital role in the development of retinal leukostasis in DR patients. ${ }^{6,7}$

Due to the rising magnitude of DR and its consequences, understanding the pathophysiology of PDR is pivotal, especially of ICAM- 1 and its role in progression of PDR and complications. Therefore, we aimed to investigate the concentration ICAM-1 in PDR patients related to glycemic status, the duration of diabetes and the use of hypoglycemic agents.

\section{Materials and methods}

\section{Study design}

A cross-sectional study was conducted from June 2015 to August 2016; T2DM patients with PDR were considered for enrollment into the study, held in Vitreoretinal Division, Department of Ophthalmology, Faculty of Medicine Universitas Indonesia (FMUI) - $\mathrm{CMGH}$, Jakarta, Indonesia. The study has received ethical clearance from the Ethic Research Committee, FMUI (350/UN2.F1/ETIK/IV/2016). Written informed consent was obtained from all patients prior to their enrollment in this study.

In this study, all eligible participants underwent systemic evaluation, which included duration of DM, measurement of blood pressure and level of serum $\mathrm{HbA1c}$.

\section{Inclusion and exclusion criteria}

Inclusion criteria were T2DM patients who have been diagnosed with PDR and were planned for pars plana vitrectomy (PPV). Patients who were recruited must have no prior history of intravitreal bevacizumab or laser photocoagulation. 
Patients who suffered from uncontrolled hypertension (systolic $>180 \mathrm{mmHg}$ or diastolic $>110 \mathrm{mmHg}$ ), coagulation disorder or using anticoagulant within the last 1-week, kidney failure (hemodialysis patients), history of stroke, congestive heart failure and collagen disorder (rheumatoid arthritis, systemic lupus erythematous or systemic sclerosis) were excluded from the study. In addition, patients with severe vitreous haemorrhage, who were unable to be examined for their fundus and optical coherence tomography, were excluded.

\section{Patients' enrollment}

Consecutive vitreous sampling was done and 33 samples were recruited. Data regarding duration of $\mathrm{T} 2 \mathrm{DM}$, level of $\mathrm{HbA} 1 \mathrm{c}$, insulin use and mean of vitreous ICAM-1 level were obtained.

\section{Vitreous and plasma samples}

Undiluted vitreous fluid samples $(0.5-1.0 \mathrm{ml})$ were harvested from 33 patients with PDR by PPV. Vitreous samples were collected with $1 \mathrm{ml}$ syringe and transferred into sterile tubes and put into a container filled with blue ice/dry ice. Afterwards, samples were frozen rapidly at $-80^{\circ} \mathrm{C}$ until assayed. Blood samples were also collected into vacuum tubes, and directly sent to the laboratory for $\mathrm{HbA1c}$ examination.

\section{Pars plana vitrectomy}

PPV was performed using the standard three-port incisions in combination with dissection and removal of the vitreous haemorrhage and FVM. Endolaser retinal photocoagulation was done in each eye with the power of 300 to $500 \mathrm{~mW}$, duration of 200 to $300 \mathrm{~ms}$, interval of 200 to $300 \mathrm{~ms}$ and number of laser shots 300 to 600 . Silicone oil was used as tamponade in all participants.

\section{Measurement of ICAM-1}

ICAM-1 level was measured from the vitreous samples by the Department of Clinical Pathology, FMUI-CMGH, Jakarta, Indonesia. Evaluation of ICAM-1 in vitreous was performed by using human ICAM-1/CD54 non-allele-specific Quantikine kit (DCIM00; sensitivity test $0.053 \mathrm{ng} / \mathrm{ml}$; intra-assay coefficient variation 4.04\%; inter-assay coefficient variation 6.28\%) for enzyme-linked immunosorbent assay. The standard solution $(50 \mu \mathrm{l}$ for ICAM-1) and the sample (50 $\mu \mathrm{l}$ for ICAM-1) were put in to the wells of a well plate coated with the relevant monoclonal antibody. The assay procedure was done according to the manufacture's instruction (R\&D systems). The intra-assay precision and the amount of the product was then quantitated as nanogram per milliliter ( $\mathrm{ng} / \mathrm{ml})$.

\section{Statistical analysis}

All statistical analyses were performed with Microsoft Excel 2007 and Statistical Package for Social Sciences Software for Windows, version 21.0 (SPSS Inc., Chicago, IL). P-value of less than 0.05 was considered significant. 


\section{Results}

Thirty-three eligible PDR patients were included in this study. The characteristics of the subjects were described in Table 1. Participants who had uncontrolled glycemic status tend to have lower vitreous ICAM-1 compared to those with controlled glycemic status. However, the difference was not found to be statistically significant ( $p=0.65$, Table 2$)$.

Participants who had T2DM for more than 10 years also had higher level of vitreous ICAM- 1 than participants with less than 10 years duration of T2DM.

Table 1. Main clinical features of diabetic patients with PDR in the study

\begin{tabular}{|l|l|}
\hline Characteristic & Control $(\mathbf{n}=\mathbf{3 3})$ \\
\hline Age (range), years & $51(26-66)$ \\
\hline Sex (\%) & \\
\hline Male & $14(42.4 \%)$ \\
\hline Female & $19(57.6 \%)$ \\
\hline Duration of diabetes (range), years & \\
\hline$\leq 10$ years ( $=21)$ & $2.5(1-10)$ \\
\hline$>10$ years $(\mathrm{n}=12)$ & $17.5(11-30)$ \\
\hline HbA1c (range), \% & \\
\hline$\leq 7$ ( $\mathrm{n}=6)$ & $6.5(5.3-7)$ \\
\hline$>7$ ( $\mathrm{n}=28)$ & $8.9(7.2-13.5)$ \\
\hline Use of hypoglycemic agent (\%) & \\
\hline With insulin & $12(36.4 \%)$ \\
\hline Without insulin & $21(63.6 \%)$ \\
\hline
\end{tabular}

Table 2. The influence of $\mathrm{HbA} 1 \mathrm{c}$ level in the concentration of vitreous ICAM-1 in PDR patients

\begin{tabular}{|l|l|l|l|}
\hline \multirow{2}{*}{ Level } & \multicolumn{2}{|l|}{ Glycemic control (HbA1c) } & \multirow{2}{*}{} \\
\cline { 2 - 4 } & Controlled $(\leq 7$ g/dl) & Uncontrolled $(>\mathbf{7} \mathbf{g} / \mathbf{d l})$ & $\mathbf{p}$ \\
\hline Mean ICAM-1 $(\mathrm{ng} / \mathrm{ml}) \pm$ SD & $24.20 \pm 13.05$ & $21.61 \pm 13.29$ & $0.650^{\text {a }}$ \\
\hline
\end{tabular}


Nevertheless, there was no statistically significant difference between both groups ( $p=0.64$, Table 3 ).

We also found that participants with insulin had higher level of vitreous ICAM-1 compared to those without insulin. However, there was no statistically significant difference between groups ( $p=0.55$, Table 4).

Table 3. The influence of diabetes duration in the concentration of vitreous ICAM-1 in PDR patients

\begin{tabular}{|l|l|l|l|}
\hline \multirow{2}{*}{ Level } & \multicolumn{2}{|l|}{ Duration of diabetes } & \multirow{2}{*}{} \\
\cline { 2 - 3 } & $\leq 10$ years & $>10$ years & p \\
\hline Mean ICAM-1 $(\mathrm{ng} / \mathrm{ml}) \pm$ SD & $24.17 \pm 14.85$ & $26.30 \pm 10.42$ & $0.643^{\text {a }}$ \\
\hline
\end{tabular}

${ }^{\text {a }} p$-value by unpaired T-Test

$\mathrm{SD}$, standard deviation

Table 4. The influence of insulin therapy in the concentration of vitreous ICAM-1 in PDR patients

\begin{tabular}{|l|l|l|l|}
\hline \multirow{2}{*}{ Level } & \multicolumn{2}{|l|}{ Use of hypoglycemic agents } & \multirow{2}{*}{} \\
\cline { 2 - 3 } & With insulin & Without insulin & p \\
\hline Mean ICAM-1 $(\mathrm{ng} / \mathrm{ml}) \pm$ SD & $27.07 \pm 10.95$ & $24.17 \pm 13.88$ & $0.551^{\text {a }}$ \\
\hline
\end{tabular}

${ }^{a} p$-value by unpaired T-Test

$\mathrm{SD}$, standard deviation

\section{Discussion}

Hyperglycemia leads to the progression of DR by increasing intraocular inflammatory activity, inducing retinal endothelial dysfunction and damaging bloodretinal barrier $(\mathrm{BRB}){ }^{8}$. The role of inflammatory factors and cytokines in the progression of DR, including ICAM-1, has been researched in many studies. ${ }^{8}$ The aim of this study was to determine the level of vitreous ICAM-1 in PDR patients and identify ICAM-1-affecting factors, including $\mathrm{HbA} 1 \mathrm{c}$ level, duration of T2DM and use of insulin. A total of 33 eligible subjects with diagnosis of PDR were collected. In this study, $57.6 \%$ of subjects were female and $42.4 \%$ were male.

One factor that can influence the concentration of ICAM-1 is the duration of T2DM. Ghonaim and El-Edel ${ }^{9}$ reported an increase of the serum ICAM-1 level in patients who suffered from T2DM for more than 10 years. They believed that the duration of T2DM would induce micro-vascular complication that provoked endothelial expression of adhesion molecules. We also found an increase of 
vitreous ICAM-1 level in participants who had suffered from T2DM for more than 10 years. Nevertheless, this result was not statistically significant. As the duration of diagnosis was obtained from interview, this result may include recall bias.

Several authors have reported the level of ICAM-1 in DR. Mroczek et al. ${ }^{8}$ found that vitreous ICAM-1 concentration in PDR patients was higher than the control group ( $19.58 \pm 20.65 \mathrm{ng} / \mathrm{ml}$ and $4.12 \pm 3.14 \mathrm{ng} / \mathrm{ml}$, respectively). In addition, other studies have been reported a significant increase of vitreous ICAM-1 in patients with diabetes compared with non-diabetic patients. ${ }^{10,11}$ A study found that ICAM-1 in patients with active PDR was higher than in those with inactive PDR. ${ }^{12}$ Nevertheless, Ruszkowska-Ciastek et al. ${ }^{13}$ showed that there was a significant decrease of serum ICAM-1 level in uncontrolled T2DM patients (HbA1c $>6.5 \%$ ) compared with well-controlled group ( $\mathrm{HbA} 1 \mathrm{c}<6.5 \% ; \mathrm{p}<0.05)$. Noda et al. ${ }^{14}$ also showed that the level of ICAM-1 was substantially reduced in subjects with $\mathrm{HbA} 1 \mathrm{C}$ $>10 \%$. We found similar result with Ruszkowska-Ciastek and Noda's studies. Our study demonstrated that vitreous ICAM-1 concentration in uncontrolled T2DM $(\mathrm{HbA} 1 \mathrm{c}>7 \%)$ was lower than in participants with well-controlled T2DM. Yet, our study observed no statistical differences in ICAM-1 level between both groups $(p>0.05)$. Unfortunately, the exact nature of this phenomenon is still not yet fully understood.

The BRB consists of an outer component, the retinal pigment epithelium and an inner component, the retinal vascular endothelium. ${ }^{15}$ ICAM- 1 is believed to be produced in the retinal pigment epithelium by the influence of VEGF expression. ${ }^{16}$ In hyperglycemic condition, the increase of ICAM-1 level mediates leukocytes adhesion to the retinal vessels influencing the vascular permeability, leading to retinal endothelial cell injury and death. This circumstance may lead to BRB breakdown and sub-endothelial basement membrane stiffness. ${ }^{17}$ Yet, after a certain period of time, we assumed that ICAM-1 level might decrease because the entire BRB layer and vascular basement membrane has already broken down. This might be the possible reason of our findings in this study. Stratifying the data based on disease duration with large sample size may help.

The usage of insulin has been believed to affecting the level of ICAM-1 in DM patients. King et al. ${ }^{18}$ and Jingi et al. ${ }^{19}$ suggested that retinal capillary endothelium was insulin-sensitive tissue. Hirata et al. ${ }^{20}$ reported that the expression of ICAM-1 increased in healthy human retinal endothelial cells incubated with $100 \mu \mathrm{U} / \mathrm{ml}$ insulin therapy for 48 hours. They demonstrated that acute-intensive insulin therapy induced the production of cell adhesion molecules on retinal endothelium, including ICAM-1. In this study, vitreous ICAM-1 level in T2DM participants with insulin was higher than T2DM patients with hypoglycemic drugs, yet there was no statistically significant difference between both the groups. T2DM participants from the insulin group in this study were treated by conventional insulin 
therapy, whereby they regularly got insulin injections of a mixture of rapid and long-acting insulin. Thus, we assumed that conventional insulin therapy might not have any direct effect in increasing the level of ICAM-1 concentration in vitreous.

\section{Conclusion}

ICAM-1 has been known to have a correlation with the progression of DR, by up-regulating VEGF and inducing retinal vascular endothelial inflammation. We concluded that conventional insulin therapy might not have direct effect on the vitreous ICAM-1 concentration. On the other hand, uncontrolled T2DM remained a controversial factor in influencing the level of ICAM-1. Limitation of our study includes presence of blood in the vitreous. Although those with severe haemorrhage were excluded, some may still have some amount of blood in the vitreous. Hence, this might affect the results. In addition, other control parameters, such as western blot, were not done. This might influence the sensitivity of the procedure to determine the result. We recommend further investigation could be conducted in order to understand the pathogenic mechanism of retinal micro-vascular abnormality in diabetic patients. Moreover, utilizing more than one method for detecting ICAM-1 may be essential for increasing the accuracy of the result.

\section{References}

1. Silva PAS, Cavallerano JD, Sun JK, et al. Proliferative diabetic retinopathy. In: Ryan SJ, et al. Retina. 5th ed. Philadelphia: Elsevier; 2013:1020-1048. https://clinicalgate.com/ proliferative-diabetic-retinopathy-2/

2. Flethcer EC, Chong NV. Retina. In: Riordan-Eva P, Whither JP (Eds) Vaughan \& Asbury's General Ophthalmology. 17th ed. London: McGraw Hill; 2007. chapter 10.

3. Fauci AS, Kasper DL, Longo DL, et al. Diabetes mellitus. In: Fauci AS, Kasper DL, Longo DL, Braunwald E, Hauser SL, Jameson Jl, et al. Harrison's Principles of Internal Medicine. 17th ed. USA: The McGraw-Hill; 2008. chapter 338.

4. Vitreoretinal Division, Department of Ophthalmology, Faculty of Medicine, University of Indonesia. Prevalence of diabetic retinopathy. Unpublished raw data; 2013.

5. Limb GA, Webster L, Soomro H, Janikoun S, Shiling J. Platelet expression of tumour necrosis factor-alpha (TNF-a), TNF receptors and intercellular adhesion molecule-1 (ICAM-1) in patients with proliferative diabetic retinopathy. Clin Exp Immunol. 1999;1 18:213-218. https://www.ncbi. nlm.nih.gov/pubmed/10540181

6. Mroczek JA, Mlynczak JPO, Hojlo MM. Proliferative diabetic retinopathy-the influence of diabetes control on the activation of the intraocular molecule system. Diabetes Res Clin Pract. 2009;84:46-50. DOI: 10.1016/j.diabres.2009.01.012

7. Zhang K, Ferreyra HA, Grob S, Bedell M, Zhang JJ. Diabetic retinopathy: genetics and etiologic mechanisms. In: Ryan SJ, et al. (Eds), Retina. 5th ed. Philadelphia: Elsevier; 2013:975-985. https:// clinicalgate.com/diabetic-retinopathy-genetics-and-etiologic-mechanisms/ 
8. Mroczek JA, Mlynczak JO. Assessment of selected adhesion molecule and proinflammatory cytokine levels in the vitreous body of patients with type 2-diabetes role of the inflammatory immune process in the pathogenesis of proliferative diabetic retinopathy. Graefes Arch Clin Exp Ophthalmol. 2008;246:1665-1670. DOI: 10.1007/s00417-008-0868-6

9. Ghonaim MM, El-Edel RH. Circulating cell adhesion molecules (sICAM-1 and SVCAM-1) and microangiopathy in diabetes mellitus. Ibnosina J Med BS. 2015;7(6):211-218. http://journals.sfu. ca/ijmbs/index.php/ijmbs/article/view/522/1085

10. Joussen $A M$, Poulaki $V$, Le $M L$, et al. A central role for inflammation in the pathogenesis of diabetic retinopathy. FASEB J. 2004;18:1450-1452. DOI: 10.1096/ij.03-1476fje

11. Yan $Y$, Zhu L, Hong L, Deng J, Song Y, Chen X. The impact of ranibizumab on the level of intercellular adhesion molecule type 1 in the vitreous of eyes with proliferative diabetic retinopathy. Acta Ophthalmol. 2016;94:358-364. DOI: 10.1111/aos.12806

12. El-Asrar AMA, Nawaz MI, Kangave D, et al. High-mobility group box-1 and biomarkers of inflammation in the vitreous from patients with proliferative diabetic retinopathy. Mol Vis. 2011;17:1829-1838. https://www.ncbi.nlm.nih.gov/pubmed/21850157

13. Ruszkowska-Ciastek B, Sokup A, Wernik T, et al. Effect of uncontrolled hyperglycemia on levels of adhesion molecules in patients with diabetes mellitus type 2. J Zhejiang Univ Sci B. 2015;16(5):355-361. DOI: 10.1631/jzus.B1400218

14. Noda K, Nakao S, Zandi S, Sun D, Hayes KC, Hafezi-Moghadam A. Retinopathy in a novel model of metabolic syndrome and type 2 diabetes: new insight on the inflammatory paradigm. FASEB J. 2014;28(5):2038-2046. DOI: 10.1096/fj.12-215715

15. Huang G, Gandhi JK, Zhong X, et al. TNF-a is required for late BRB breakdown in diabetic retinopathy, and its inhibition prevents leukostasis and protects vessels and neurons from apoptosis. 2011 Mar 10;52(3):1336-44. doi: 10.1167/iovs.10-5768. Print 2011 Mar.

16. Nagineni CN, Kutty RK, Detrick B, Hooks JJ. Inflammatory cytokine induce intercellular adhesion molecule-1 (ICAM-1) mRNA synthesis and protein secretion by human retinal pigment epithelial cell cultures. Cytokine. 1996 Aug; 8(8):622-630.

17. Qaum $T, X u$ Q, Joussen $A M$, et al. VEGF-initiated blood retinal barrier breakdown in early diabetes. Retina. 2001 Sept; 42(10):2408-2413.

18. King GL, Buzney SM, Kahn CR, et al. Differential responsiveness to insulin of endothelial and support cells from micro- and macrovessels. J Clin Invest. 1983;71:974-979. https://www.ncbi. nlm.nih.gov/pubmed/6339562

19. Jingi AM, Noubiap JJ, Essouma M, et al. Association of insulin treatment versus oral hypoglycemic agents with diabetic retinopathy and its severity in type 2 diabetes patients in Cameroon, sub-Saharan Africa. Ann Transl Med. 2016 Oct;4(20):395. DOI: 10.21037/ atm.2016.08.42

20. Hirata F, Yoshida M, Niwa Y, et al. Insulin enhances leukocyte endothelial cell adhesion in the retinal microcirculation through surface expression of intercellular adhesion molecule-1. Microvasc Res. 2005;69:135-141. DOI: 10.1016/j.mvr.2005.03.002 